\title{
The role of immune checkpoint inhibitors in prostate cancer
}

\author{
Gabriel Surdacki ${ }^{1, A-E}$, Aneta Szudy-Szczyrek ${ }^{2, C, E}$, Aneta Gorący ${ }^{2, C, E}$, Katarzyna Chyl-Surdacka ${ }^{3, A-B, E}$, \\ Marek Hus ${ }^{2, C, E-F}$ \\ 1 Department of Urology and Urological Onkology, The name of John of the God Hospital, Lublin, Poland \\ 2 Department of Haematooncology and Bone Marrow Transplantation, Medical University of Lublin, Poland \\ ${ }^{3}$ Department of Dermatology, Venerology and Paediatric Dermatology, Medical University of Lublin, Poland \\ A - Research concept and design, B - Collection and/or assembly of data, C - Data analysis and interpretation, \\ $D$ - Writing the article, E - Critical revision of the article, $F$ - Final approval of article
}

Surdacki G, Szudy-Szczyrek A, Gorący A, Chyl-Surdacka K, Hus M. The role of immune checkpoint inhibitors in prostate cancer. Ann Agric Environ Med. 2019; 26(1): 120-124. doi: 10.26444/aaem/96331

\begin{abstract}
Introduction. Prostate cancer (PC) is the most commonly diagnosed malignant tumour and the third cause of cancer deaths among men in Europe. The treatment of early-stage PC is very effective and in many cases allows achievement of a complete cure, whereas the treatment of metastatic prostate cancer (mPC) is still a huge challenge for clinicians. New therapeutic strategies for $\mathrm{MPC}$ are urgently needded. One of the most promising methods of treatment is anticancer immunotherapy including the monoclonal antibodies against immune checkpoint inhibitors.

Objectives. To present the potential possibilities of using checkpoint inhibitors blockage in the treatment of $\mathrm{mPC}$, and to overview the results of recent research on immune checkpoint inhibitors in patients with PC.

State of knowledge. Recent studies suggest that monoclonal antibodies directed against immune checkpoint inhibitors in combination with traditional therapy may become a breakthrough in the treatment of $\mathrm{mPC}$ in the near future.

Conclusions. The immunotherapy using monoclonal antibodies against immune checkpoint inhibitors seems to be a new opportunity for patients with advanced PC. The key to achieve the maximum anti-tumour response is to choose the best candidates for this therapy and determine the optimal sequence and combination of drugs. The introduction of immunotherapy as the standard treatment of patients with advanced PC requires further studies.
\end{abstract}

\section{Key words}

prostate cancer, checkpoint inhibitor, PD-1, PD-L1, CTLA-4

\section{INTRODUCTION}

Prostate cancer (PC) is the most commonly diagnosed malignant tumour and the third cause of cancer deaths among men in Europe [1]. The treatment options for men with early-stage PC are radical prostatectomy, radiotherapy or brachytherapy [2]. These are very effective therapies and in many cases allow to achieve a complete cure.

The treatment of metastatic prostate cancer (mPC) is still a huge challenge for clinicians. The standard therapeutic strategy for $\mathrm{mPC}$ is the use of surgical or pharmacology castration aimed at reducing the levels of testosterone $[2,3]$. This results in delayed disease progression and improves the quality of life of patients with mPC.

The most serious clinical problem is that in the course of treatment PC becomes refractory to hormone manipulation, known as metastatic castration-resistant prostate cancer (mCRPC) $[2,4]$. There are many options for the treatment of mCRPC including docetaxel, abiraterone acetate, enzalutamide, cabazitaxel, radium-223, Sipuleucel-T (the only cancer vaccine approved to treat advanced PC so far) $[3,4,5,6,7,8]$, and radioligand therapy (RLT) directed against prostate-specific membrane antigen PSMA, which could be successfully used as a third line therapy of mCRPC $[9,10,11]$.

Address for correspondence: Gabriel Surdacki, Department of Urology and Urological Onkology, The name of John of the God Hospital, Lublin, Poland e-mail: gabriel.surdacki@wp.pl

Received: 15.05.2018; accepted: 27.09.2018; first published: 26.11 .2018
However, mCRPC remains still a disease with a fatal outcome. The average survival time for patients ranges from a few to more than a dozen months. New therapeutic strategies for $\mathrm{mCRPC}$ are urgently required. One of the most promising treatment is anticancer immunotherapy, including the monoclonal antibodies against immune checkpoint inhibitors [12]. Ipilimumab - a monoclonal antibody directed against CTLA-4 is currently under investigation for the treatment of advanced PC $[5,13,14,15]$. The other immune checkpoint, the blockage which could be successfully used in the treatment of $\mathrm{mCRPC}$, is the $\mathrm{PD}-1$ programmed death receptor.

Immune checkpoint inhibitors. Immune checkpoint inhibitors (PD-1 programmed death receptor and CTLA 4-receptor) are part of the so-called immune synapse and act as negative regulators of the immune response. Together with other T-cell receptors (TCRs) they regulate a healthy balance between an effective immune response (including anticancer response) and tolerance to autoantigens. Their over-expression down-regulates T-cell activation to eliminate the cancer cells.

T-cells activity is determined by some interactions with their ligands in consequence of contact with antigen presenting cell (APC). Lymphocytes require two kinds of signals within the immune synapse to become fully activated. The first signal occurs when the T-cell receptor binds to antigen presented on the surface of antigen presenting cells (APC). The second is derived from the co-stimulatory receptors (e.g. CD28, 
ICOS) or co-inhibitory receptors (CTLA 4 and PD-1) $[4,5$, $16,17,18]$. Predominant co-inhibitory signaling lead to T lymphocytes anergy or apoptosis instead of their activation and anticancer activity. This mechanism is used by cancer cells. It has been noticed that an over-expression of ligands for co-inhibitory receptors is observed in many cancers, which in effect leads to the escape of tumour cells from the host immune system $[5,17,18,19]$.

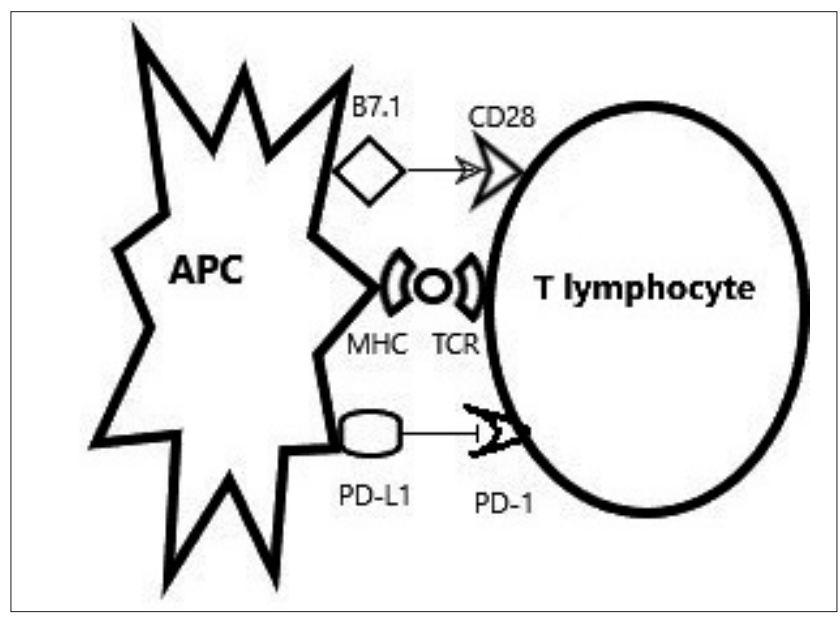

Figure 1. Interactions between antigen presenting cell (APC) and T lymphocytes

Immune checkpoint inhibitors in prostate cancer. The results from studies on the expression of co-inhibitory ligands (eg. PD-L1) on cells and stroma of PC are equivocal. Some studies report that PC cells do not have primarily increased PD-L1 expression [5, 12, 20, 21, 22, 23, 24]. However, it was found that the infiltration of the tumour microenvironment by antitumour immune cells (including CD8 T lymphocytes) secondarily leads to high expression of co-inhibitory ligands (eg. PD-L1). This phenomenon is known as 'acquired immunity' $[6,7,20]$. In this way the PC cells avoid elimination by the host immune system.

There are also the studies confirming primarily high PD-1 expression on cells and stroma of PC $[19,25,26]$. Gevensleben et al. showed in a study of a cohort of 902 PC patients that there was not only a high PD-L1 expression in PC cells, but also found that it is an independent negative prognostic factor of biochemical-failure-free survival (BFFS). [19]. This suggests the potential association between $\mathrm{PD}-\mathrm{L} 1$ expression and primary aggressive PC [19, 25].

Most published studies report a high expression of PD-1 receptors on immune cell clusters (CD4 and CD8 lymphocytes) surrounding PC lesions $[5,21,25,26,27]$. A highly expressed PD-L1 receptors on lymphocytes affecting the cancer cells leads to their increased apoptosis or anergy and to their lack of anti-tumour activity in effect [1]. An association was also reported between a high-grade histology (according to Gleason score) PC and the number of PD-1 positive cells detected in peripheral blood and in tumour [12, 21]. In a study of a group of 535 patients who underwent radical prostatectomy for $\mathrm{PC}$, it was found that the high density of PD-1 (+) lymphocytes was a significant, independent negative prognostic factor of disease-free survival [25].

Impact of monoclonal antibodies directed against immune checkpoint inhibitors in the treatment of PC. The concept that the PD-1 and CTLA 4 receptors could be used by tumours to escape immune attack led to the development of many studies on the use of immune checkpoint inhibitors in cancer therapy. The use of monoclonal antibodies targeting these molecular pathways could lead to a more effective elimination of tumour cells by $\mathrm{T}$ lymphocytes. Nivolumab (anti-PD-1 monoclonal antibody) and Iplimumab (antiCTLA4 monoclonal antibody) have already been approved for the treatment of kidney cancer, non-small cell lung cancer and melanoma $[2,4,17,28,29,30]$. Clinical trials of ipilimumab in advanced PC are also being carried out $[4,5$, $7,15,21]$. In phase I / II trial in 50 patients with metastatic castration-resistant PC (mCRPC) investigating ipilimumab showed a PSA decline of 50\% PSA in 8 patients [31].

Results from two large phase III randomized trials demonstrated a prolongation of progression-free survival and decline of PSA in patients with CRPC treated with iplimumab $[14,15]$. First study was conducted in 799 patients who progressed after Docetaxel therapy. They were divided into two groups: one was the group of patients who underwent radiotherapy for bone metastases and iplimumab therapy, while the othergroup received radiotherapy and placebo. It was found that the median progression free survival in the Iplimumab group was 4.0 months, in contrast to 3.1 months in the placebo group (median 4.0 [95\% CI 3.6-4.3] vs 3,1 [2.9-3.4] months; HR 0.70, 95\% CI 0.61-0.82; $\mathrm{p}<0.0001$ ). The results also showed that treatment with Iplimumab improved progression free survival after 6 months, compared to placebo (30.7\% vs $18.1 \%$ of patients) [14]. A second study of 602 chemotherapy naive mCRPC patients tested single-agent ipilimumab vs placebo. The study indicated that median progression free survival was better in the Iplimumab group -5.6 months, than in the placebo group -3.8 months (hazard ratio: $0.67 ; 95.87 \% \mathrm{CI}, 0.55-0.81$ ) [15].

The first attempts to use nivolumab as a monotherapy in PC patients were not very promising. In three independent clinical trials, no objective clinical response was found in a total of $27 \mathrm{PC}$ patients [7, 12, 19, 23, 24, 25, 29, 32]. This could have been caused by an unconfirmed increased expression of PD-L1 on cancer cells in these patients $(<5 \%$ PD-L1 positive cells) $[19,23,24]$. Therefore, on this basis, no major conclusions can be drawn on the efficacy of nivolumab treatment in PC patients.

There is a hypothesis that only a selected group of patients (with high expression of PD-1, PD-L1 on cancer cells) could benefit from the mentioned therapy $[19,25]$. However, some studies have shown that the most important biomarker to the PD-1/PD-L1 blockade efficacy was the expression of PD-L1, not only on the cancer cells, but also on hosts antigen presenting cells (APCs) $[33,34]$. A study conducted on multiple tumour-bearing mouse models demonstrated the loss of therapeutic efficacy of PD-L1 blockade in immunodeficient mice, PD-1 and PD-L1 - deficient mice [33]. This could suggest that the host immune system is essential for the efficacy of this method of therapy. It has also been found that a high PD-L1 expression on host APCs (particularly dendritic cells and macrophages) in the tumour-draining lymph nodes and its microenvironment is connected with higher efficacy of PD-1/PD-L1 blockade. The same conclusions have been drawn in some studies of metastatic melanoma and ovarian cancer patients treated with PD-1 and CTLA- 4 blockade. The percentage of PD-L1(+) dendritic cells and PD-L1(+) macrophages strictly correlated with clinical responses to treatment [33]. A predictive role 
of the PD-L1 expression on tumour surroundings has also been hypothesized. In response to monoclonal antibodies directed against checkpoint inhibitors the activated $\mathrm{T}$ cells can migrate into tumour tissue and contribute an appropriate response for the treatment [34].

Subsequent studies suggest that the most effective strategy in the treatment of mCRPC may be the combination of immunotherapy with traditional therapy $[4,6,7]$. Combined anti-androgen ablation with anti-PD1 or anti-CTLA-4 antibodies seems to be particularly interesting [7]. It has been shown that anti-androgen therapy (ADT) can modulate the tumour micro-environment and temporarily lead to increase the expression of PD-L1 on T lymphocytes surrounding tumour lesions [3, 20,35]. This indicates the potentially synergistic effect of ADT treatment with anti PD-1 antibodies. Mouse studies have shown that the highest efficacy of immunotherapy can be achieved after using anti-androgen ablation $[3,4,36]$. These findings were also confirmed in randomized trials in patients with nonmetastatic CRPC evaluated an antiandrogen - nilutamid and a viral vaccine against PSA. A clinical benefit has been shown compared with nilutamide as monotherapy $[3,37$, 38]. The significant difference in median OS was shown in a study with 42 non-metastatic CRPC patients: 3.4 years in nilutamid arm vs 6.2 years in viral vaccine + nilutamid arm $(\mathrm{P}=0.045)$. In contrast, in another study of patients with a rising PSA levels after primary radical therapy (radical prostatectomy or radiotherapy), there was no significant decrease in PSADT (PSA doubling times) in patients who received bicalutamide and iplimumab.

A synergistic effect was also observed of monoclonal antibodies directed against immune checkpoint inhibitors using simultaneously with anticancer vaccines in PC [4]. In several studies, the combination of these two groups of drugs demonstrated improvement in the anti-tumour efficacy of the vaccines $[4,29]$. The use of a DNA vaccine encoding prostatic alkaline phosphatase (PAP), together with a blockade of the $\mathrm{PD}-1 / \mathrm{PD}-\mathrm{L} 1$ pathway, resulted in better clinical responses to treatment and a longer time to disease progression [29]. This is due to the fact that anti-tumour vaccination of PC effectively abolishes the resistance to immunizations by a blockade of the PD-1/ PD-L1 pathway (an increased expression of PD-L1 on patients' circulating tumour cells). This correlation was also observed in PC patients treated with sipuleucel-T [29].

It was also found that a resistance to enzalutamide (a drug used to treat $\mathrm{mCRPC}$ ) is associated with strong PD-1/PD-L1 expression in tumour microenvironment and on circulating dendritic cells, indicating that this group of patients could be a potential target for anti-PD-1 therapy [12]. In the group of patients with enzalutamide-resistant PC, the use of pembrolizumab (anti-PD-1 monoclonal antibody) have yielded a stable and deep responses to treatment $[25,39,40]$.

The therapeutic synergy of the combination of EBRT (external beam radiation therapy) and iplimumab (monoclonal anti-CTLA-4 antibody) has also been confirmed $[4,7,31,41]$. A phase III trial in patients with mCRPC who had progressed after docetaxel chemotherapy, compared iplimumab in combination with palliative radiotherapy for bone metastases to radiotherapy alone. The addition of ipilimumab to radiotherapy significantly prolonged the time to progression [14].

Studies are also being carried out to evaluate correlations between PD-1 expression on circulating virgin T lymphocytes or PD-L1 expression on tumour cells and the response to anti PD-1 therapy. This would improve the identification of PC patients in whom immunotherapy would be more effective $[12,19]$. First reports confirm this hypothesis. In a clinical study of 23 patients with advanced PC and high PD-L1 expression on cancer/stromal cells, the use of pembrolizumab (anti-PD-1 monoclonal antibody) yielded a stable response to treatment [42].

Predictive markers for checkpoint inhibitor-based immunotherapy in PC. Checkpoint inhibitors blockage therapy seems to be a very promising option for patients with PC. However, based on previous studies, it can be concluded that only a part of the patients could benefit from this therapy. There is a need to identify some predictive biomarkers which could help adequately qualify to treatment and allow improvementof its effectiveness. One of the most important predictive factors seems to be the PD-L1 expression on the cancer and stromal cells [19]. However, evaluation of this

Table 1. Results of research on the effectiveness of monoclonal antibodies directed against immune checkpoint inhibitors in the treatment of patients with metastatic prostate cancer

\begin{tabular}{|c|c|c|c|c|}
\hline Author & Study & Patient population & Therapy & Results \\
\hline Slovin SF. et al. [28] & NCT00323882 & 50 patients & $\begin{array}{l}\text { Iplimumab } 10 \mathrm{mg} / \mathrm{kg}+\text { EBRT (8 Gy/lesion) vs } \\
\text { Iplimumab } 10 \mathrm{mg} / \mathrm{kg} \text { monotherapy }\end{array}$ & $\begin{array}{l}\text { PSA decline of } 50 \% \text { reported in } 8 \text { patients. } \\
\text { one patient confirmed complete response } \\
\text { with time to response of } 2.5 \text { months. } \\
\text { Six patients had stable disease lasting } \\
\text { between } 2.8-6.1 \text { months. }\end{array}$ \\
\hline Kwon ED. et al. [11] & NCT00861614 & $\begin{array}{l}799 \text { patients who had } \\
\text { progressed after docetaxel } \\
\text { chemotherapy }\end{array}$ & $\begin{array}{l}\text { Iplimumab 10mg/kg + EBRT vs placebo + } \\
\text { EBRT }\end{array}$ & $\begin{array}{l}\text { Improved progression free survival and post- } \\
\text { treatment PSA reductions more frequent in } \\
\text { the Ipilimumab group. }\end{array}$ \\
\hline Beer TM. et al. [12] & NCT01057810 & 602 patients & Iplimumab $10 \mathrm{mg} / \mathrm{kg}$ vs placebo & $\begin{array}{l}\text { Iplimumab increases progression-free } \\
\text { survival and prostate-specific antigen } \\
\text { response rates. }\end{array}$ \\
\hline Brahmer JR. et al. [29] & NCT00729664 & 17 patients & $\begin{array}{l}\text { Nivolumab } 0.3-10 \mathrm{mg} / \mathrm{kg} \text { every } 14 \text { days in } \\
6 \text {-week cycles }\end{array}$ & No objective responses. \\
\hline Graff JN. et al. [34] & NCT02312557 & $\begin{array}{l}20 \text { patients progressing after } \\
\text { enzalutamide therapy }\end{array}$ & $\begin{array}{l}\text { Pembrolizumab } 200 \text { mg IV every } 3 \text { weeks for } \\
4 \text { doses with continued enzalutamide }\end{array}$ & $\begin{array}{l}\text { Profound and durable responses to PD-1 } \\
\text { inhibition with enzalutamide. }\end{array}$ \\
\hline Hansen A. et al. [37] & NCT02054806 & $\begin{array}{l}23 \text { patients with high } \\
\text { expression of } \mathrm{PD}-\mathrm{L} 1\end{array}$ & $\begin{array}{l}\text { Pembrolizumab } 10 \mathrm{mg} / \mathrm{kg} \text { administered every } \\
2 \text { weeks for up to } 24 \text { months or up to disease } \\
\text { progression }\end{array}$ & $\begin{array}{l}\text { Pembrolizumab resulted in durable } \\
\text { responses in heavily pretreated patients } \\
\text { with advanced PD-L1-positive PC. }\end{array}$ \\
\hline
\end{tabular}


expression is difficult and requires a tumour biopsy. The expression of PD-L1 on APCs and the PD-1 expression on circulating $\mathrm{T}$ lymphocytes could also have predictive significance $[33,34]$. Further research is still required to identify predictive biomarkers for immunotherapy.

Side-effects of checkpoint inhibitors. The most common adverse effects of checkpoint inhibitors are related with its natural activity, and present such as the inhibition of immune response both to hosts antigens and protection against the development of autoimmune diseases [6]. Treatment related side-effects are associated with excessive activity of the immune system and affected mainly the digestive system (diarrhea, colitis, hepatotoxicity), skin (rash, pruritis), neurological system (myasthenia, neuropathy), endocrine disorders (adrenal insufficiency, hopo/hyper-thyroidism, hypopituitarism, hot flashes, gynaecomastia), fatigue and anemia. The treatment of adverse effects consists mainly in administering immunosuppressive drugs (corticosteroids, infliximab, tacrolimus, mycophenolate mofetil, antihistaminics) and supportive care $[1,6,14,16,17,19,21,26$, 40]. In some cases, the side- effects were so severe that they led to discontinuation of the treatment, or even the death of patients $[14,17]$.

\section{CONCLUSIONS}

The immunotherapy using monoclonal antibodies seems to be a new opportunity for patients with advanced PC. Recent studies suggest that monoclonal antibodies directed against immune checkpoint inhibitors in combination with traditional therapy may become a breakthrough in the treatment of mCRPC in the near future. The key to achieving the maximum anti-tumour response is to determine the optimal sequence and combination of drugs and appropriate selection of patients using predictive biomarkers [4]. Further research is needed to enable the introduction of immunotherapy as the standard treatment of patients with advanced PC.

\section{REFERENCES}

1. Ferlay J, et al. Estimates of cancer incidence and mortality in Europe in 2008. Eur J Cancer. 2010; 46: 765-781.

2. Horwich A, Hugosson J, de Reijke T, Wiegel T, Fizazi K, Kataja V, et al. Prostate cancer: ESMO Consensus Conference Guidelines 2012. Ann Oncol Off J Eur Soc Med Oncol. 2013; 24: 1141-62.

3. McNeel DG, Smith HA, Eickhoff JC, Lang JM, Staab MJ, Wilding G, et al. Phase I trial of tremelimumab in combination with short-term androgen deprivation in patients with PSA-recurrent prostate cancer. Cancer Immunol Immunother. 2012 Jul; 61(7): 1137-47.

4. Schweizer MT, Drake CG. Immunotherapy for prostate cancer: recent developments and future challenges. Cancer Metastasis Rev. 2014 Sep; 33(2-3): 641-55

5. Barach YS, Lee JS, Zang X. T cell coinhibition in prostate cancer: new immune evasion pathways and emerging therapeutics. Trends Mol Med. 2011; 17(1): 47-55.

6. Boikos SA, Antonarakis ES. Immunotherapy for prostate cancer enters its golden age. Clin Med Insights Oncol. 2012; 6: 263-73

7. Alberti C. Prostate cancer immunotherapy, particularly in combination with androgen deprivation or radiation treatment. Customized pharmacogenomic approaches to overcome immunotherapy cancer resistance. G Chir. 2017 Sep-Oct; 37(5): 225-235.

8. McNeel DG, Bander NH, Beer TM, Drake CG, Fong L, Harrelson S, et al. The Society for Immunotherapy of Cancer consensus statement on immunotherapy for the treatment of prostate carcinoma. J Immunother Cancer. 2016 Dec 20; 4: 92.

9. Edler von Eyben F, Roviello G, Kiljunen T, Uprimny Ch, Virgolini I, Kairemo K, et al. Third-line treatment and 177 Lu-PSMA radioligand therapy of metastatic castration-resistant prostate cancer: a systematic review. Eur J Nucl Med Mol Imaging. 2018; 45(3): 496-508.

10. Rahbar K, Schmidt M, Heinzel A, Eppard E, Bode A, Yordanova A, et al. Response and Tolerability of a Single Dose of 177 Lu-PSMA-617 in Patients with Metastatic Castration-Resistant Prostate Cancer: A Multicenter Retrospective Analysis. J Nucl Med. 2016 Sep; 57(9): 1334-8.

11. Afshar-Oromieh A, U Haberkorn, Zechmann Ch, Armor T, Mier W, Spohn F, et al. Repeated PSMA-targeting radioligand therapy of metastatic prostate cancer with 131I-MIP-1095. Eur J Nucl Med Mol Imaging. 2017; 44(6): 950-959.

12. Bishop JL, Sio A, Angeles A, Roberts ME, Azad AA, Chi KN, et al. PD-L1 is highly expressed in Enzalutamide resistant prostate cancer. Oncotarget. 2015; 6(1): 234-42.

13. Kwek SS, Cha E, Fong L. Unmasking the immune recognition of prostate cancer with CTLA4 blockade. Nat Rev Cancer. 2012; 12: 289-97.

14. Kwon ED, Drake CG, Scher HI, Fizazi K, Bossi A, van den Eertwegh AJM, et al. Ipilimumab versus placebo after radiotherapy in patients with metastatic castration-resistant prostate cancer that had progressed after docetaxel chemotherapy (CA184-043): a multicentre, randomised, double-blind, phase 3 trial. Lancet Oncol. 2014; 15: 700-12.

15. Beer TM, Kwon ED, Drake CG, Fizazi K, Logothetis C, Gravis G, et al. Randomized, Double-Blind, Phase III Trial of Ipilimumab Versus Placebo in Asymptomatic or Minimally Symptomatic Patients With Metastatic Chemotherapy-Naive Castration-Resistant Prostate Cancer. J Clin Oncol. 2016; JCO691584.

16. Modena A, Ciccarese C, Iacovelli R, Brunelli M, Montironi R, Fiorentino $\mathrm{M}$, et al. Immune Checkpoint Inhibitors and Prostate Cancer: A New Frontier? Oncol Rev. 2016; 10(1): 293.

17. Krawczyk P, Wojas-Krawczyk K. Przeciwciała monoklonalne przeciw immunologicznym punktom kontroli w leczeniu chorych na nowotwory. Onkol Prakt Klin. 2015; 11(2): 76-86.

18. Grzywnowicz M, Giannopoulos K. Znaczenie receptora programowanej śmierci 1 oraz jego ligandów w układzie immunologicznym oraz nowotworach. Acta Haematol Pol. 2012; 43(2).

19. Gevensleben H, Dietrich D, Golletz C, Steiner S, Jung M, Thiesler T, et al. The Immune Checkpoint Regulator PD-L1 Is Highly Expressed in Aggressive Primary Prostate Cancer. Clin Cancer Res. 2016; 23: 1969-77.

20. Martin AM, Nirschl TR, Nirschl CJ, Francica BJ, Kochel CM, van Bokhoven A, et al. Paucity of PD-L1 expression in prostate cancer: innate and adaptive immune resistance. Prostate Cancer Prostatic Dis. 2015 ; 18(4): 325-32.

21. Sfanos KS, Bruno TC, Meeker AK, De Marzo AM, Isaacs WB, Drake CG. Human prostateinfiltrating CD8+ T lymphocytes are oligoclonal and PD-1+ Prostate. 2009; 69(15): 1694-1703. 10.1002/pros.21020.

22. Baas W, Gershburg S, Dynda D, Delfino K, Robinson K, Nie D, et al. Immune Characterization of the Programmed Death Receptor Pathway in High Risk Prostate Cancer. Clin Genitourin Cancer. 2017 Oct; 15(5): 577-581.

23. Topalian SL, Hodi FS, Brahmer JR, Gettinger SN, Smith DC, McDermott $\mathrm{DF}$, et al. Safety, activity, and immune correlates of anti-PD-1 antibody in cancer. N Engl J Med. 2012; 366: 2443-54.

24. Taube JM, Klein A, Brahmer JR, Xu H, Pan X, Kim JH, et al. Association of PD-1, PD-1 Ligands, and Other Features of the Tumour Immune Microenvironment with Response to Anti- PD-1 Therapy. Clin Cancer Res. 2014; 20: 5064-74.

25. Ness N, Andersen S, Khanehkenari MR, Nordbakken CV, Valkov A, Paulsen EE, et al. The prognostic role of immune checkpoint markers programmed cell death protein 1 (PD-1) and programmed death ligand 1 (PD-L1) in a large, multicenter prostate cancer cohort. Oncotarget. 2017 Apr 18; 8(16): 26789-26801.

26. Massari F, Ciccarese C, Caliò A, Munari E, Cima L, Porcaro AB, et al. Magnitude of PD-1, PD-L1 and T Lymphocyte Expression on Tissue from Castration-Resistant Prostate Adenocarcinoma: An Exploratory Analysis. Target Oncol. 2015.

27. Ebelt K, Babaryka G, Frankenberger B, Stief CG, Eisenmenger W, Kirchner T, et al. Prostate cancer lesions are surrounded by FOXP3+, PD-1+ and B7-H1+ lymphocyte clusters. Eur J Cancer. 2009; 45: $1664-72$.

28. Cappuccini F, Stribbling S, Pollock E, Hill AV, Redchenko I. Immunogenicity and efficacy of the novel cancer vaccine based on simian adenovirus and MVA vectors alone and in combination with 
PD-1 mAb in a mouse model of prostate cancer. Cancer Immunol Immunother. 2016; 65(6): 701-13.

29. Rekoske BT, Olson BM, McNeel DG. Antitumour vaccination of prostate cancer patients elicits $\mathrm{PD}-1 / \mathrm{PD}-\mathrm{L} 1$ regulated antigen-specific immune responses. Oncoimmunology. 2016 Mar 28; 5(6).

30. Cabel L, Loir E, Gravis G, Lavaud P, Massard Ch, Albiges L, et al. Long-term complete remission with Ipilimumab in metastatic castrateresistant prostate cancer: case report of two patients. Cabel et al. J ImmunoTher Cancer 2017; 5: 31.

31. Slovin SF, Higano CS, Hamid O, Tejwani S, Harzstark A, Alumkal $\mathrm{JJ}$, et al. Ipilimumab alone or in combination with radiotherapy in metastatic castration-resistant prostate cancer: results from an openlabel, multicenter phase I/II study. Ann Oncol. 201310.1093/annonc/ mdt107

32. Brahmer JR, Drake CG, Wollner I, Powderly JD, Picus J, Sharfman $\mathrm{WH}$, et al. Phase I study of single-agent anti-programmed death-1 (MDX-1106) in refractory solid tumours: safety, clinical activity, pharmacodynamics, and immunologic correlates. J Clin Oncol. 2010; 28: $3167-75$

33. Lin H, Wei S, Hurt EM, Green MD, Zhao L, Vatan L, et al. Host expression of PD-L1 determines efficacy of PD-L1 pathway blockademediated tumour regression. J Clin Invest. 2018 Apr 2; 128(4): 1708

34. Tang H, Liang Y, Anders RA, Taube JM, Qiu X, Mulgaonkar A, et al. PD-L1 on host cells is essential for PD-L1 blockade-mediated tumour regression. J Clin Invest. 2018 Feb 1; 128(2): 580-588.

35. Mercader M, Bodner BK, Moser MT, Kwon PS, Park ES, Manecke RG, et al. T cell infiltration of the prostate induced by androgen withdrawal in patients with prostate cancer. Proc Natl Acad Sci U S A. 2001 Dec 4; 98(25): 14565-70.

36. Drake CG, Doody AD, Mihalyo MA, Huang CT, Kelleher E, Ravi S, et al. Androgen ablation mitigates tolerance to a prostate/prostate cancer-restricted antigen. Cancer Cell. 2005 March; 7(3): 239-249

37. Arlen PM, Gulley JL, Todd N, Lieberman R, Steinberg SM, Morin $S$, et al. Antiandrogen, vaccine and combination therapy in patients with nonmetastatic hormone refractory prostate cancer. J Urol. 2005; 174: 539-546.

38. Madan RA, Gulley JL, Schlom J, Steinberg SM, Liewehr DJ, Dahut WL, et al. Analysis of overall survival in patients with nonmetastatic castration-resistant prostate cancer treated with vaccine, nilutamide, and combination therapy. Clin Cancer Res. 2008; 14: 4526-4531.

39. Graff JN, Alumkal JJ, Drake CG. First evidence of significant clinical activity of PD-1 inhibitors in metastatic, castration resistant prostate cancer (mCRPC). Ann Oncol 2016; 27(suppl. 6).

40. Graff JN, Alumkal JJ, Drake CG, Thomas GV, Redmond WL, Farhad $\mathrm{M}$, et al. Early evidence of anti-PD-1 activity in enzalutamide-resistant prostate cancer. Oncotarget. 2016; 7(33): 52810-52817. doi: 10.18632/ oncotarget.10547.

41. Popovic LS, Matovina-Brko G, Popovic M. Checkpoint inhibitors in the treatment of urological malignancies. ESMO Open. 2017 Jun 23; 2(2).

42. Hansen A, Massard C, Ott PA, Haas N, Lopez J, Ejadi S, et al. Pembrolizumab for patients with advanced prostate adenocarcinoma: preliminary results from the KEYNOTE-028 study. Ann Oncol. 2016; 27 suppl 6: 725PD. 